Издательство социально-экономической литературы, 1960. C. $104-110$.

5. Чугаев Л.А. Дмитрий Иванович Менделеев. Биография русского гения // Экология и жизнь. 2009. № 1. С. 12-19.

6. Михайлов О.В. Легенды и были о Менделееве, русской водке и сверхкритических флюидах // Вестник Российской академии наук. 2013. Т. 83, № 4. C. $381-384$.

7. Гердт Я.В. Д.И. Менделеев о влиянии природных условий на историю, развитие и политику государства // Евразийский журнал региональных и политических исследований. 2007. № 23. С. 47-52.

8. Серёгин А.В. Монархические идеи Д.И. Менделеева // Право и государство: теория и практика. 2009. № 7. С. 105-107.

9. Егоров Г.В. Социально-гуманитарные взгляды Д.И. Менделеева // Вестник Нижегородского университета им. Н.И. Лобачевского. 2015. № 5-6. С. 41-45.

10. Козиков И.А. Российские естествоиспытатели о славянах (М.В. Ломоносов, Д.И. Менделеев, В.И. Вернадский) // Вестник Российской нации. 2009. Т. 5, № 3. С. 49-65.

11. Козиков И.А. Д.И. Менделеев об особенностях образования российского государства // Вестник Российской нации. 2011. Т. 17, № 3. С. 86-94.

12. Козиков И.А. Д.И. Менделеев о территориальной целостности России // Национальные интересы России: глобальные приоритеты, политические стратегии и перспективы: мат-лы Первого съезда Российского общества политологов. 2014. С. 614-620.
13. Козиков И.А. Великий завет Д.И. Менделеева // Вестник Российской нации. 2015. Т. 4, № 4-4 (42). C. $78-90$.

14. Гловели Г.Д. Д.И. Менделеев и евразийство // Философия хозяйства. 2009. № 2 (62). С. 252-265.

15. Козик И.А. Д.И. Менделеев и В.И. Вернадский о цивилизационных особенностях России // Проблемный анализ и государственно-управленческое проектирование. 2012. Т. 5. Вып. 6 (26). С. 123-131.

16. Исаева О.С. Об источниках геосоциологии классического евразийства // Известия высших учебных заведений. Поволжский регион. Общественные науки. 2015. С. 112-119.

17. Менделеев Д.И. Об исследовании Северного полярного океана // Проблемы экономического развития России / Д.И. Менделеев. М.: Издательство социально-экономической литературы, 1960. С. 94-101.

18. Витте С.Ю. О ледоколе «Ермак» и намерении установить морской путь на Дальний Восток по северному побережью Сибири // Витте С.Ю. Избранные воспоминания, 1849-1911 гг. М.: Мысль, 1991. C. 657.

19. Менделеев Д.И. Заветные мысли. СПб.: Типолит. М.П. Фроловой, 1903-1905. 428 с.

20. Менделеев Д.И. К познанию России. СПб.: Изд. А.С. Суворина, 1906. 160 с.

Статья публикуется в рамках выполнения гранта Президента Российской Федерации для государственной поддержки молодых российских ученых - кандидатов наук (Конкурс - МК-2017) № MK-2889.2017.6.

\title{
D.I. MENDELEEV ABOUT THE CULTURAL AND HISTORICAL TASKS OF RUSSIA IN THE EAST (C) 2018
}

Suvorov Valery Vladimirovich, candidate of historical sciences, assistant of Philosophy, Humanities and Psychology Department Saratov State Medical University named after V.I. Razumovsky (Saratov, Russian Federation)

Abstract. At the turn of the XIX-XX centuries, the movement of Russia to the East became one of the topics discussed in domestic journalism and scientific thought. His views on this issue were also expressed by the outstanding scientist D.I. Mendeleev. In his works he stressed the historical necessity and inevitability of Russia's access to the Pacific Ocean, the importance of its foreign policy development in the Far East direction. Showing the cultural and civilizational distancing of Russia from the West, he focused on the presence of eastern features in it, but at the same time he noted its cultural and historical uniqueness. In Mendeleev's discourses, a departure from Eurocentrism in the assessments of the East and Russia can be traced. Speaking about the cultural and historical tasks of Russia, the scientist stressed that it was more important to maintain the «charm» of the name in the East than to imitate Western states, especially England. In Mendeleev's papers, special emphasis was made on the peaceful strengthening of Russia in Asia and a friendly attitude towards the Eastern peoples. An interesting feature of Mendeleev's reasoning is the motif of a fairy tale: on the one hand, it is a half-sketchy east, on the other, a fairy tale as the image of an ideal future for Russia.

Keywords: Dmitri Ivanovich Mendeleev; S.Yu. Witte; Russian empire; western countries; foreign policy; cultural and historical tasks of Russia in the East; Asia; Far East; Pacific Ocean; CERD; «Treasured thoughts»; China; Japan; Russo-Japanese War; eastern peoples; Eurasianism.

УДК 93/94

Статья поступила в редакцию 22.10.2017

\section{КУЛЬТУРНЫЕ ОСОБЕННОСТИ РОССИИ-ЕВРАЗИИ В КОНЦЕПЦИИ П.Н. САВИЦКОГО} (C) 2018

Быстрюков Владимир Юрьевич, кандидат исторических наук, доцент кафедры всеобщей истории, права и методики обучения Самарский государственный соџиально-педагогический университет (2. Самара, Российская Федераџия)

Аннотащия. Статья посвящена оценке П.Н. Савицким культурных особенностей России-Евразии. Как лидер евразийства, в своих работах он исходил из концептуальной установки движения - признания особой «евразийской» цивилизации. Влияние концепта Евразия имело ключевой характер для всей концепции 
евразийства и взглядов его отдельных представителей. Реальность существования нового континента детерминировала тексты евразийцев, заставляла искать систему во множестве признаков, а в самой системе видеть упорядоченность, которая не могла быть связана ни с чем иным, как с новым континентом. Культурные особенности России-Евразии были обусловлены ее географическим расширением и политическими условиями. П.Н. Савицкий признавал огромную роль православия в истории России-Евразии. У П.Н. Савицкого Россия является «третьей великой евразийской культурой», творчески переработавшей европейские и азиатские культурные начала и вырастающей из преемства двух предшествующих. Однако эссенциализация Евразии приводила к определенным противоречиям не только во взглядах разных представителей движения, но и у каждого евразийца в отдельности. Логика развития новой цивилизации, по мнению ученого, неизбежно вела к «евразийскому будущему» России.

Ключевые слова: русская эмиграция; евразийское движение; П.Н. Савицкий; евразийская цивилизация; эллинизм и византийство; культура России; культурное творчество. культурные особенности РоссииЕвразии; культура и идеология.

В начале 20-х гг. ХХ века в Русском зарубежье возникло евразийство - идейное и общественно-политическое течение первой волны эмиграции. Огромный вклад в идейное оформление евразийства внес П.Н. Савицкий (1895-1968). Историография его работ составной частью входит в историографию движения и не всегда можно четко их разделить. «Евразийскую историософию en bloc трудно отделить от собственно мировоззрения П.Н. Савицкого. С немалым основанием его евразийство, не умаляя заслуг историков Г.В. Вернадского и М.В. Шахматова, философа и историка Л.П. Карсавина, философа права Н.Н. Алексеева, философа и богослова В.Н. Ильина, литературного критика Д.П. Святополк-Мирского, музыковеда П.П. Сувчинского, наконец, Н.С. Трубецкого, можно без особых натяжек отождествлять с позицией «первого евразийца»» [1]. Поэтому изучение взглядов П.Н. Савицкого должно способствовать более глубокому пониманию проблем и задач, которые ставили евразийцы.

Концепт Евразия являлся ключевым понятием для всех представителей нового движения. В своих работах евразийцы исходили из реальности нового континента. Объект исследования оказывал влияние и предполагал определенную логику объяснения как исторических фактов, так и современных политических событий. Интеллектуальная генеалогия Евразии имеет свои закономерности развития. Каждый из евразийцев подошел к созданию нового континента со своим запасом идей, которые формировались еще до революции, то есть в рамках русской академической традиции, которая до 1917 г., несомненно, развивалась в русле европейской науки.

Вопросы преемственности и развития культуры для русских эмигрантов имели особую значимость и остроту в силу их оторванности от России. Важную роль они играли и во взглядах евразийцев. Моделирование отдельных цивилизаций фрагментировало исторический процесс, катастрофа 1917 г. вела к негативной оценке имперского опыта истории страны. Этот опыт носил явно европейский характер. Для евразийцев это являлось подтверждением цивилизационных различий и пагубности европейского влияния [2].

Месторазвитие евразийского мира, по мнению П.Н. Савицкого, определяло культурные особенности и характеристики России-Евразии. Анализируя построения Н.С. Трубецкого в работе «Европа и Человечество» [3], в частности, его принцип «равноценности и качественной несоизмеримости всех культур и народов земного шара», П.Н. Савицкий указывал на то, что понятие «культуры» и «культурной ценности» вовсе не апеллируют в своем суще- ствовании к признаку общеобязательности и общепринятости. Согласно формулировке Г. Тарда, используемой Н.С. Трубецким, культурная ценность есть то, «что принято для удовлетворения потребностей всеми или частью представителей данного народа» [4], соответственно «культурная ценность» и не должна носить общеобязательного характера, как и «культура», как совокупность «культурных ценностей».

П.Н. Савицкий предлагал рассматривать культуру не как целостное явление, а разделить ее на отрасли. В системе культурных ценностей он выделял два основных направления. Первое было связано с идеологическим обрамлением жизни народа и включало его ценностные ориентации и самосознание. Второе было связано с инструментами, средствами достижения целей человеческого бытия. П.Н. Савицкий называл это противоположением идеологии и эмпирического знания. П.Н. Савицкий указывал на то, что могут возникать сомнения по поводу принадлежности какой-либо «культурной ценности», но это не снимает важности данного деления. Выдвинутый Н.С. Трубецким принцип «равноценности» он считал возможным приложить только к сфере «идеологии», но не к технике и эмпирическому знанию. Он критиковал Н.С. Трубецкого за «излишне обобщенные формулировки», приводившие к «идеализации дикарей и проповеди культурной слабости». В качестве основания для сравнения различных культур П.Н. Савицкий предлагал использовать фактор устойчивости или силы, которую они проявляют при взаимоотношениях. «Существенность этого факта заключается в том, что выживают и приобретают историческое значение только те культуры, которые при соприкосновении с другими оказываются достаточно сильными, чтобы отстоять свое существование хотя бы в одном из указанных отношений - или в военно-политическом или в отношении культурных влияний» [4].

П.Н. Савицкий предлагал сузить противопоставление Европы и человечества, как это было у Н.С. Трубецкого, до противопоставления Европы и России, выделяя два существенных факта. Первый заключается в мировом значении русской литературы и изобразительного искусства XIX в., второй - в таком историческом явлении, как большевизм. Но П.Н. Савицкий не хотел противопоставлять Европе, рассматриваемой как культурное целое, просто страну. Он предлагал противопоставить другое культурное целое - «Евразию», наделяя ее не только геоморфологическими особенностями, но и своеобразными культурно-историческими чертами. «Противоположение это питается и в идеологическом и в милитарном отношении силами не одной этнографической России, но целого круга примыкающих к ней 
туранских, монгольских, арийских, иверских, финских народов» [4]. То, что до революции называлось Российской империей, было названо Евразией, особой цивилизацией, и культурная многозначность стала одним из проявлений ее силы и устойчивости.

Концепт «Евразия» представлял собой особый культурный внутренне единый в бесконечном многообразии проявлений мир, своеобразную «культуро-личность». Этот термин вошел во все манифесты движения 20-30-х гг. [5-7]. В одном из них указывалось, что географические особенности, особое мироощущение, особенности наречий языкового союза (здесь сказалось влияние работ Р.О. Якобсона) народов России-Евразии являются признаками своеобразия евразийской культуры. Проживающие на евразийском пространстве народы гораздо ближе друг другу, нежели народам, представляющим другие месторазвития и цивилизации. Подобный набор цитат можно привести из работ всех основных евразийских авторов. Так или иначе, все евразийские работы были посвящены доказательству ее реальности и раскрытию ее свойств, зримо и незримо новый континент присутствовал во всех их работах, иначе они не были бы «евразийскими».

П.Н. Савицкий отрицательно относился к делению народов на «передовые» и «отсталые», считал, что культуру следует рассматривать по отраслевому принципу, учитывая социальную среду. Созданная в «своем» социуме культурная ценность не может и не должна иметь всеобщее значение, ее значение субъективно и не может быть подвержено объективной оценке универсалистского подхода. «Культурная среда, низко стоящая в одних отраслях культуры, может оказаться, и сплошь и рядом оказывается, высоко стоящей в отраслях других. Нет никакого сомнения, что жители острова Пасхи в Великом океане «отставали» от современных англичан по весьма многим отраслям эмпирического знания и техники; это не помешало им в своей скульптуре проявить такую меру оригинальности и творчества, которая недоступна ваянию современной Англии» [8]. Отрицая европоориентированные подходы к истории цивилизаций, П.Н. Савицкий считал, что оценка взаимоотношений между культурами относится к области «философской свободы»» [9].

Дифференцированное рассмотрение культуры, по мнению П.Н. Савицкого, дезавуирует понятие универсального прогресса и делает невозможным «градацию народов» по уровням культурного развития. «Если линия эволюции разно пролегает в разных отраслях, то не может быть и нет общего восходящего движения, нет постепенного неуклонного общего совершенствования: та или иная культурная среда и ряд их, совершенствуясь в одном и с одной точки зрения, нередко упадает в другом и с другой точки зрения» [10].

П.Н. Савицкий писал, что российская культура является «евразийской», поскольку она творчески переработала элементы отдельных цивилизаций, сделав их своими. В своем историческом развитии она испытала влияние соседних культур. На историческом этапе с X по XIII вв. преобладающее влияние оказывал Юг, который был представлен византийской культурой. Последнюю (как и предшествующую ей эллинистическую культуру), П.Н. Савицкий также называл «евразийской». Византийская культура действительно может соответствовать термину «евразийская», поскольку симбиоз греческого христианства и язычества народов Ближнего Востока и Северной Африки позволял так ее называть. В принципе об эллинистическом евразийском мире в работах евразийцев не сказано практически ничего. Эллинистическая культура, то есть тонкий слой городских жителей, размазанный по ближневосточному месторазвитию, вряд ли соответствует термину «евразийская» (если мы мыслим в русле дискурса П.Н. Савицкого), поскольку элементы европейской и азиатской культуры входили в очень непрочное объединение. С Византией возникает традиция, имевшая ключевое значение для евразийства, - православие. Что касается эллинистического мира, то такая традиция отсутствует. Но присутствует географическая связь между месторазвитием эллинизма и византизма - то есть Балканы, Ближний Восток, Северная Африка. Для концепции евразийства такое совпадение имело смысл. Такая же традиция возникает у России относительно Монгольской империи.

В середине XIII в. влияние Юга сменилось влиянием Востока, «степной» цивилизации Монгольского государства. Евразийцы всегда подчеркивали, что в становлении России пребывание в составе Золотой Орды сыграло ключевую роль, а связи с азиатскими культурами для нашей страны не менее важны, чем с европейской. C XV в. постепенно нарастает влияние Запада. Своего максимума оно достигает в XVIIIXIX вв., в европейской империи Романовых. Евразийцы считали, что в это время русская нация раскололась на два субстрата. Первый - элита - оказалась в сфере влияния европейской культуры, второй простой народ - остался в рамках традиционной культуры. Закономерным итогом «европейского» вектора развития России стала революция 1917 г. Но для П.Н. Савицкого и для евразийцев она стала точкой отсчета нового этапа развития России, нового этапа ее исторического развития. «Чем была Россия, - спрашивал он, - ощущавшая себя частью Европы, входившая в систему европейских держав, как это было во весь период империи? Несмотря на всю свою политическую силу, в культурном отношении она чувствовала себя, а часто была третьестепенной Европой» [11].

В своей работе «Миграция культуры» П.Н. Савицкий применил геополитический подход к классификации культурных центров мировой истории [12]. Взяв за главный критерий нижний предел температуры, он составил схему перемещения главных культурных центров. Здесь он выявил закономерность, которая заключалась в перемещении культурных центров от менее холодных областей к более холодным. П.Н. Савицкий спрогнозировал дальнейшее продвижение культурных центров в области Северной Америки и Евразии, то есть в зоны со средней годовой температурой около $0^{\circ} \mathrm{C}$.

В новом «постреволюционном» культурном строительстве России должна помочь самостоятельная культурная традиция, достаточная для того, чтобы быть независимой от Европы. В своих работах 30-х гг. П.Н. Савицкий пытался обнаружить в культурной жизни Советского Союза тенденции, так или иначе связанные с русской культурной традицией. В 1937 г., уже на излете существования евразийского движения как некой организации П.Н. Савицкий видел элементы традиции в современной ему советской действительности, причем они заявляли о себе до- 
статочно четко и определенно [13]. Он указывал на следующие признаки: во-первых, возродился интерес к истории России, особенно в сравнении с 1920ми гг., во-вторых, снова актуализировалось понятие «национальное единство». П.Н. Савицкому казалось, то сталинский режим интегрирует марксизм и русский национализм. «Советский Союз на 90\% живет старой русской культурой XIX века, и теперь культура в России и культура в эмиграции есть единая русская культура» [13].

В одной из своих работ П.Н. Савицкий писал, что эмиграции государство должна заменить идея, пока она же реально не создаст само «государство, средоточие и вождя». П.Н. Савицкий утверждал, что в полной мере идеи в жизни не осуществляются, тем не менее они проступают в исторической действительности. Он критиковал внешнюю культурную политику СССР, обращал внимание на необходимость утверждения форм массового искусства, в том числе и современного - моды и кинематографа. Он считал, что мировые горизонты развития культуры способны сплотить народы евразийского пространства сильнее, чем государственная политика. «Не «комплекс второсортности», но мироводительство - вот лозунг русско-евразийской культуры в ближайший и уже начинающийся период» [14]. И поэтому для П.Н. Савицкого был неприемлем этнический национализм украинский, белорусский, русский, - это он называл «комплексом второсортности».

Становление и утверждение России-Евразии как самостоятельной культурной среды должно помочь развитию отношений с другими культурами и цивилизациями. «Чтобы сблизиться с Европой, нужно стать духовно и материально независимыми от нее... Чем своеобразнее мир, чем оригинальней культура, тем больше своих особых вопросов он может поставить. И вопросы эти, примененные к другим мирам и культурам, освещают неожиданным светом эти последние... Каждый народ должен быть личностью. А личность единственна и неповторима. И как раз единственностью и неповторимостью своей ценна для других» [11].

Во второй половине 30-х гг. П.Н. Савицкий специфически рассматривал культурные процессы в СССР. Национальное единство, «старый русский национализм», старая русская культура XIX в. оценивались, безусловно, положительно, хотя в 20-е гг. последние два понятия жестко критиковались. Однако эти элементы традиции, проступающие сквозь советскую действительность, свидетельствовали в конечном итоге о закономерностях Евразии. Достижение «национального единства» («единства Евразии»), являлось одной из ее целеполаганий.

Большое значение для евразийства в целом и для него отдельных представителей имела тема религиозного отношения к миру. Особенно ярко это ощущалось в начале истории движения, когда в его состав входил известный богослов Г.В. Флоровский. Православие представлялось как основа новой истинной идеологии. Именно такой взгляд был отражен в одном из манифестов евразийского движения. «Каждый, кто умаляет или отодвигает в сторону религиозную природу евразийства, - делает злое и неправое дело» [15].

П.Н. Савицкий писал, что большевизм и латинство, интернационал и Ватикан в эмпирическом и историческом отношении соратники и союзники. Образ Европы, чуждый, а иногда и враждебный, при ближайшем рассмотрении оказывался размытым и нечетким [16]. В работах П.Н. Савицкого очень мало говорится об особенностях европейской цивилизации. «Русскость оказалась несовместимой с латинством, а латинство, в свою очередь, оказалось несовместимым с осуществлением объединительной роли в пределах евразийского мира» [17] и возможность заимствования европейской техники - вот в принципе и все мысли относительно европейской культуры, чье влияние П.Н. Савицкий так страстно обличал. Европа нужна евразийцам в качестве «другого Я». Не будь ее, нечего было бы сочетать с азиатскими элементами и творчески перерабатывать в евразийскую культуру. Антиевропеизм носит идеологический характер, как и Евразия он предшествует анализу исторического процесса, а не вытекает из него.

Таким образом, П.Н. Савицкий ставил знак тождества между терминами «российская» и «евразийская» культуры. Своеобразие первого понятия он выводил из бытия второго, которое в свою очередь определялось органичным сочетанием различных цивилизаций. Отталкивание от Европы - это квинтэссенция евразийства. Два века западного влияния привели к революции 1917 г. - этот посыл проходит красной нитью через большинство их работ. Однако это не мешало П.Н. Савицкому утверждать, что в 1937 г. СССР живет старой русской культурой XIX в. и поэтому составляет единое целое с эмиграцией.

Несмотря на антирелигиозность коммунистической власти, П.Н. Савицкий считал, что коммунизм тем не менее зиждется на определенном религиозном основании, хотя само оно, несомненно, принадлежит злому началу. Но сам факт существования религиозного основания для П.Н. Савицкого был лучше, нежели вообще отсутствие таковых [18]. Основная задача евразийства, по мысли П.Н. Савицкого, состоит в связи социального вопроса, со всей ясностью и остротой поставленного революцией 1917 г., и религии. Утверждение особого мира России-Евразии приведет к сближению с другими цивилизациями и культурами. «... Коммунистическое решение не кажется... ни подлинным, ни окончательным... Оно связано во многих чертах с определенными сторонами русской истории, выражает их и в себе несет. Но во многом оно символизирует худшие стороны русской истории, выражает собой ее ограниченность» [11]. Лидер евразийства был абсолютно уверен, что рано или поздно коммунистический этап истории нашей страны сменится этапом евразийским [19].

Евразийцы, писавшие об особом культурном мире и русской науке, творили в русле традиции, неразрывно связанной с европейской, в рамках современного им политического европейского спектра, поисков европейских интеллектуалов. Это противоречие отражало место евразийства в русской историко-философской мысли. Выстраивание самостоятельной историософской традиции для особого мира «России-Евразии» [20] было неотделимо от западной культуры, науки и цивилизации. Евразийство, с одной стороны, было итогом развития национальной школы, с другой - активным участником современных европейских и мировых споров и дискуссий. 
Список литературы:

1. Дурновцев В.И., Савицкий П.Н. // Историки России XVIII-XX веков. Вып. 6. М., 1999. С. 111-123.

2. В поисках Евразии. Общественно-политическая и научная деятельность П.Н. Савицкого в годы эмиграции (1920-1938 гг.). Самара: Самарское книжное издательство, 2007. 280 с.

3. Трубецкой Н.С. Европа и Человечество // Наследие Чингисхана / Н.С. Трубецкой. М., 1999. С. 29-90.

4. Савицкий П.Н. Европа и Евразия // Континент Евразия / П.Н. Савицкий. М.: Аграф, 1997. С. 141-160.

5. Евразийство (опыт систематического изложения). Париж: Евразийское книгоиздательство, 1926. 80 с.

6. Евразийство (Формулировка 1927 г.) // Евразийская хроника. Париж, 1927. Вып. 9. С. 3-14.

7. Евразийство: декларация, формулировка, тезисы. Прага: Евразийское книгоиздательство, 1932. $30 \mathrm{c}$.

8. Савицкий П.Н. Географический обзор РоссииЕвразии // Континент Евразия / П.Н. Савицкий. М.: Аграф, 1997. С. 279-294.

9. Савицкий П.Н. В борьбе за евразийство // Континент Евразия / П.Н. Савицкий. М.: Аграф, 1997. C. $161-216$.

10. Савицкий П.Н. Евразийство // Континент Евразия / П.Н. Савицкий. М.: Аграф, 1997. С. 81-97.
11. Савицкий П.Н. Евразийство как исторический замысел // Континент Евразия / П.Н. Савицкий. М.: Аграф, 1997. С. 98-112.

12. Савицкий П.Н. Миграция культуры // Исход к Востоку. М.: Добросвет, 1997. С. 120-139.

13. Савицкий П.Н. Россия и эмиграция (культурно-историческая проблематика момента) // Новый град. Париж, 1938. № 13. С. 114-127.

14. Савицкий П.Н. Великороссия и Украина в русской культуре // Родное слово. Варшава. 1926. № 8. С. $10-14$.

15. Савицкий П.Н. Задание евразийства // Евразийский сборник. Прага, 1929. Кн. 6. С. 4-5.

16. Савицкий П.Н. Россия и латинство // Россия и латинство. Берлин: Евразийское книгоиздательство, 1923. C. 9-15.

17. Савицкий П.Н. Геополитические заметки по русской истории // Начертание русской истории / Г.В. Вернадский. СПб.: Лань, 2000. С. 285-310.

18. Савицкий П.Н. К обоснованию евразийства // Руль. 1922. № 349. 10 янв.

19. Савицкий П.Н. Подданство идеи // Континент Евразия / П.Н. Савицкий. М.: Аграф, 1997. С. 127-133.

20. Савицкий П.Н. Сила традиций и сила творчества // Континент Евразия / П.Н. Савицкий. М.: Аграф, 1997. С. 138-139.

\section{CULTURAL PECULIARITIES OF RUSSIA-EURASIA IN SAVITSKIY'S CONCEPTION}

(C) 2018

Bystryukov Vladimir Yurevich, candidate of historical sciences, associate professor of World History, Law and Methods of Teaching Department Samara State University of Social Sciences and Education (Samara, Russian Federation)

Abstract. The paper is aimed at P.N. Savitskiy's evaluation of cultural peculiarities of Russia-Eurasia. As a leader of the Eurasianism, he based his works on the main idea of the movement, which is the acceptance of «Eurasian» civilization. The influence of the Eurasia concept was the key point to the whole concept of the Eurasianship and the views of its individual representatives. The reality of a new continent existence determined the texts of Eurasianists, made it necessary to search for the system in a variety of features, and in the system itself to see an ordering that could not be connected with anything else than with a new continent. Cultural peculiarities of Russia-Eurasia were conditioned by its geographic expansion and its political factors. P.N. Savitskiy admitted the importance of the Orthodox Church in Russia-Eurasia history. According to P.N. Savitsky's mind Russia is «the third great Eurasian culture». However, the essentializing of Eurasia led to certain contradictions in the views of different representatives of the movement as well as of each Eurasian. According to the scientist, the manner of the new civilization development led inevitably to the «Eurasian» Russian future.

Keywords: Russian emigration; Eurasian movement; P.N. Savitsky; Eurasian civilization; Hellenism and Byzantinism; Culture of Russia; folklore; cultural peculiarities of Eurasianism; culture and ideology.

\section{МЕТОДОЛОГИЧЕСКИЕ ОСОБЕННОСТИ ИЗУЧЕНИЯ ИСТОРИЧЕСКОГО МОДЕЛИРОВАНИЯ АСИММЕТРИЧНЫХ КОНФЛИКТОВ}

(C) 2018

Малкин Станислав Геннадьевич, доктор исторических наук, доцент, заведующий кафедрой всеобщей истории, права и методики обучения

Самарский государственный соииально-педагогический университет (2. Самара, Российская Федераиия)

Аннотащия. В настоящей статье анализируются методологические особенности изучения роли наследия империй в политике ведущих держав в странах третьего мира сквозь призму исторического моделирования асимметричных конфликтов. Особое внимание уделено роли этого аналитического метода в определении курса внешней политики Великобритании и США после Второй мировой войны, в эпоху «холодной войны» во второй половине XX в. и «глобальной войны с террором» в начале XXI в. Обращается внимание не только на методологические ловушки (такие, как вероятность исследования проблемы по заданной переменной и терминологическая путаница), но и на исследовательские возможности, которые открывает такой подход в области исторического и политического анализа (такие, как, например, формирование более предметного представления об эволюции теории и практики международных отношений в условиях трансформации ми- 